\title{
Appendix B: Float Operators
}

This documentation was generated from the Python documentation available by typing help(float) in the Python shell. In this documentation at least one of the variables $x$ and $y$ refer to floats. The official Python 3 documentation is at http://docs. python.org $/ 3 /$.

\begin{tabular}{l|l|l}
\hline Operator & Returns & Comments \\
\hline $\mathrm{x}+\mathrm{y}$ & float & Returns the sum of $\mathrm{x}$ and $\mathrm{y}$ \\
\hline $\mathrm{x}-\mathrm{y}$ & float & Returns the difference of $\mathrm{x}$ and $\mathrm{y}$ \\
\hline $\mathrm{x}$ y & float & Returns the product of $\mathrm{x}$ and $\mathrm{y}$ \\
\hline $\mathrm{x} / \mathrm{y}$ & float & Returns the quotient of $\mathrm{x}$ divided by $\mathrm{y}$ \\
\hline $\mathrm{x} \% \mathrm{y}$ & float & $\begin{array}{l}\text { Returns the quotient of integer division of } \mathrm{x} \text { divided } \\
\text { by } \mathrm{y} . \text { However, the result is still a float }\end{array}$ \\
\hline abs(x) & float & $\begin{array}{l}\text { Returns } \mathrm{x} \text { modulo } \mathrm{y} \text {. This is the remainder of dividing } \\
\mathrm{x} \text { by } \mathrm{y}\end{array}$ \\
\hline $\operatorname{divmod}(\mathrm{x}, \mathrm{y})$ & Returns the absolute value of $\mathrm{x}$ \\
\hline float(x) & $(\mathrm{q}, \mathrm{r})$ & $\begin{array}{l}\text { Returns the quotient } \mathrm{q} \text { and the remainder } \mathrm{r} \text { as a tuple. } \\
\text { Both } \mathrm{q} \text { and } \mathrm{r} \text { are floats, but integer division is } \\
\text { performed. The value } \mathrm{r} \text { is the whole and fractional } \\
\text { part of any remainder. The value } \mathrm{q} \text { is a whole number }\end{array}$ \\
\hline $\operatorname{int}(\mathrm{x})$ & Returns the float representation of $\mathrm{x}$ \\
\hline $\operatorname{pow}(\mathrm{x}, \mathrm{y})$ & float & Returns the floor of $\mathrm{x}$ as an integer \\
\hline repr(x) & float & Returns $\mathrm{x}$ to the $\mathrm{y}$ power \\
\hline $\operatorname{str}(\mathrm{x})$ & str & Returns a string representation of $\mathrm{x}$ \\
\hline
\end{tabular}

